\title{
Success with neurotropin in treating pediatric lower extremity pain induced by spinal cord injury after epidural anesthesia
}

This article was published in the following Dove Press journal:

Journal of Pain Research

6 June 2017

Number of times this article has been viewed

\section{Mengye Zhu',* \\ Fuqing Zhou ${ }^{2, *}$ \\ Lingchao $\mathrm{Li}^{\prime}$ \\ Qin Yin ${ }^{3}$ \\ Mizhen Qiu' \\ Yong Zhang'}

'Department of Pain Clinic, ${ }^{2}$ Department of Radiology, The First Affiliated Hospital of Nanchang University, Nanchang, ${ }^{3}$ Department of Pain Clinic, The Affiliated Hospital of Xuzhou Medical University, Xuzhou, People's Republic of China

*These authors contributed equally to this work
Correspondence: Yong Zhang Department of Pain Clinic, The First Affiliated Hospital of Nanchang University, 17 Yongwaizhen Street, Nanchang 330006, Jiangxi, People's Republic of China Email zy830226@163.com
Abstract: Spinal cord injury (SCI) complicated by epidural anesthesia, though rare, can result in neuropathic pain. However, the treatment for this kind of life-altering injury remains a challenge. A 7-year-old girl was referred with dyskinesia and severe pain in her right lower extremity due to an accidental SCI following lumbar puncture. After treatment with analgesics such as gabapentin, mecobalamin, and dexamethasone/methylprednisolone for 1 week, the myodynamia had improved, but progressive pain persisted. After treatment with neurotropin, a gradual decrease in visual analog scale score from 7 to 0 was observed. We herein first describe that neurotropin produced sustained relief of pain induced by SCI. This case suggests that neurotropin might be a promising drug in treating pediatric neuropathic pain caused by SCI.

Keywords: spinal cord injury, pain, neurotropin, children

\section{Introduction}

Spinal cord injury (SCI) remains a significant problem causing great damage to physical systems and functional abilities. Although mainly caused by spine fracture or dislocation, ${ }^{1,2}$ SCI can also result from lumbar puncture during an epidural block. ${ }^{3}$ Because drugs such as lidocaine and its analogs can be injected into the subarachnoid space, epidural anesthesia has rare, but serious complications such as epidural or spinal subarachnoid hemorrhage and arachnoiditis, thus causing SCI with dyskinesia and chronic pain. ${ }^{46}$ Several pain treatments have been widely studied. However, neurotropin, which has been known to regulate neuronal growth, has not yet been reported to treat SCI pain caused by epidural anesthesia in children. We herein describe a case of SCI complicated by epidural anesthesia successfully treated with neurotropin.

\section{Case report}

A 7-year-old girl was hospitalized in a local hospital on April 2, 2015. Her height and weight were $130 \mathrm{~cm}$ and $20 \mathrm{~kg}$, respectively. She was diagnosed with appendicitis and underwent emergency appendectomy with epidural anesthesia (midline approach to T12-L1 interspace) combined with propofol sedation.

Her past medical history was noncontributory. During appendectomy, her vital signs remained stable. One incident, however, occurred during the course of anesthesia. A transient involuntary movement occurred while performing the lumbar puncture with $1 \%$ lidocaine, causing the anesthetic needle to penetrate to a depth of $15 \mathrm{~mm}$ (a depth of $\sim 25 \mathrm{~mm}$ was first measured, but $15 \mathrm{~mm}$ was finally confirmed by the anesthetist). Because of the possibility of SCI, the patient was treated with dexamethasone (injection, $5 \mathrm{mg}$ ) in 
the local hospital to reduce inflammation and eliminate local potential edema. After the end of anesthesia, the patient woke up without mental disorder or disturbance of consciousness, but then complained of pain with a visual analog scale (VAS) score of 4, pinching, fatigue and numbness in the right lower extremity, and impaired walking. Tenderness to palpation was found as hyperesthesia of the skin on the right lower leg and hyperalgesia on the right side of the above area (Figure 1). Magnetic resonance imaging (MRI) showed an increased abnormal T2 signal found in the T12-L1 level spinal cord (Figure 2). The MRI result indicated that her symptoms seemed to result from the unexpected needle puncture.

Because of the possibility of SCI, gabapentin, mecobalamin, diclofenac sodium, ganglioside, and pulsed methylprednisolone were administered for analgesia and neuroprotection.

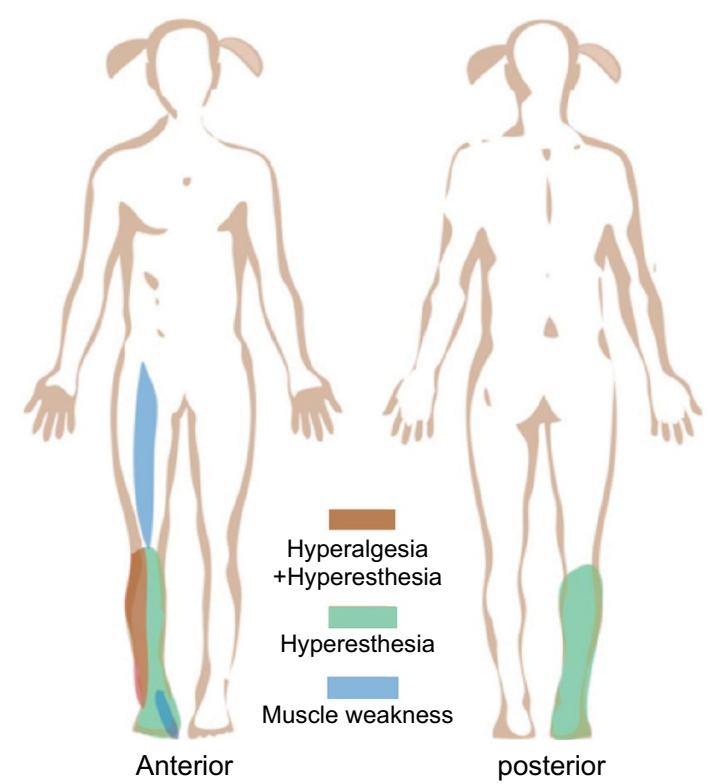

Figure I Images illustrating the subregion of hyperalgesia, hyperesthesia, and muscle weakness.

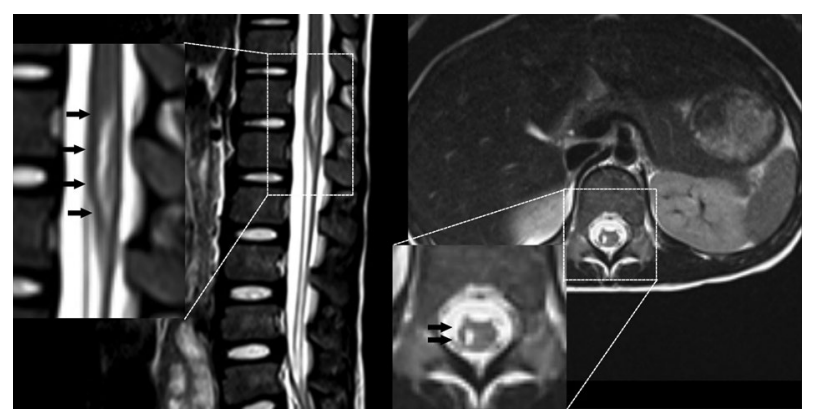

Figure 2 Emergency MRI after the girl recovered from anesthesia in the local hospital.

Note: The black arrows show the location of cord injury.

Abbreviation: MRI, magnetic resonance imaging.
The patient recovered gradually. The myodynamia, measured by the Lovett muscle strength grading scale, improved after corticosteroid treatment for 7 days. However, the patient did not achieve any pain relief, so she was then transferred from the local hospital to our department on April 11, 2015, which was the ninth postoperative day.

After transferring, she expressed more frequent and more aggravated spontaneous pain during the night, which often lasted for about an hour each time with a VAS score of 7. We then found that the area of hyperesthesia within her right leg originated in the lumbar segments L4-S1, associated with muscle atrophy or weakness involving the right quadriceps femoris, peroneus longus, and brevis. Furthermore, the Achilles reflex on the right had disappeared without any pathologic signs.

Recent clinical and basic studies verified the effectiveness of neurotropin on analgesia and neuroprotection while treating neuropathic pain as well as primary headache..$^{7-12}$ Meanwhile, one Japanese report established the safety of neurotropin when used in childhood. To achieve sustained pain relief, we obtained informed consent from the patient's parents and approval from the Medical Research Ethics Committee of the First Affiliated Hospital of Nanchang University. We then treated the patient with neurotropin (3.6 units/day, intravenously guttae, purchased from Nippon Zoki Pharmaceutical Co. Ltd.) combined with gabapentin (200 $\mathrm{mg}$, per os, three times per day).

During the next few days, the patient's clinical symptoms of neuropathic pain and motor disorder started to improve, but the repeat MRI result (Figure 3A) did not reveal any healing, still indicating the myelomalacia of SCI and spinal cord swelling. On the fifth day after the described treatment, the patient's thermal hyperalgesia disappeared. After another week of treatment, her myodynamia was fully recovered (from grade III to grade IV+), while the pain was significantly alleviated

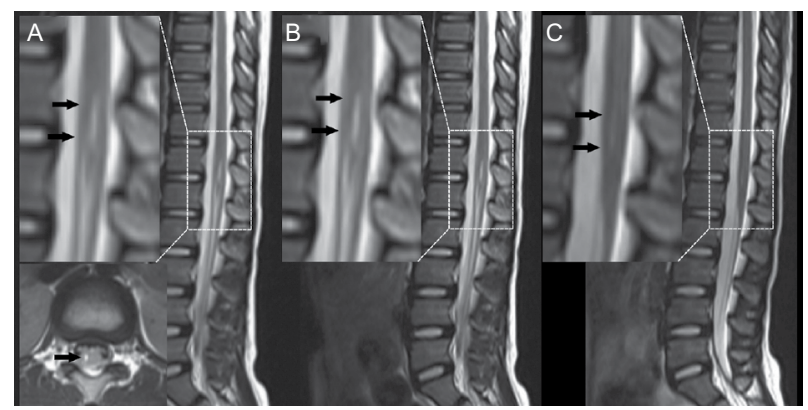

Figure 3 Repeat MRI after the administration of neurotropin.

Notes: (A and B) Sagittal MRI shows the cord injury after the 14th and 30th days of continual treatment, respectively; (C) the myelomalacia of $\mathrm{SCl}$ nearly disappeared after about 15 months after continual treatment. The black arrows show the location of cord injury.

Abbreviations: MRI, magnetic resonance imaging; $\mathrm{SCl}$, spinal cord injury. 
and the VAS score decreased from 7 to 4 . The patient was then discharged from our hospital after assessment that her condition did not affect her daily life. After leaving the hospital, she continued to take neurotropin orally. Several days later, the patient's cutaneous superficial sensation gradually improved, and her Achilles reflex fully recovered. One month later, none of her neurologic symptoms persisted, while the MRI result indicated the recovery of SCI as well (Figure 3B). Fifteen months later, the MRI result (Figure 3C) confirmed that the myelomalacia of SCI had nearly disappeared. Ultimately, this young patient went back to school as a recovering child.

When we finished the treatment, the patient's parents provided written informed consent for publication of the case details.

\section{Discussion}

Epidural anesthesia is fundamental to pain relief for children when operating in the lower extremity and hypogastrium. ${ }^{13}$ It is generally safe but can be associated with complications, especially for pediatric patients due to their immature mentality, which can make them uncooperative. In this case, physical injury induced by excessive probing predominantly accounted for the patient's suffering.

In fact, neuralgia after epidural anesthesia is rare, but it may induce severe pain, which should be taken seriously. Several other factors can also result in neurologic injury. For example, anesthetics at high local concentration exert neurotoxic effects, while epinephrine, a vasoconstrictor, increases the duration and quality of anesthesia, but theoretically induces tissue ischemia. ${ }^{14}$ Furthermore, neurotoxic medications mistakenly administered and patient's pre-existing pathology, such as coagulopathy, causing an epidural hematoma directly causing neuralgia, can also be risk factors. ${ }^{15}$ Appropriate and timely medication administration is crucial for the treatment of SCI. In this case, the initial treatment followed the generally accepted strategy of administering glucocorticoids, dehydrants, analgesics, anticonvulsants, and antidepressants to treat the neuropathic pain induced by SCI complicated by epidural anesthesia, ${ }^{16,17}$ but no pain relief was achieved within the first week. Specific to this case, our patient received a total of 3.6 units/day of neurotropin for pain treatment. Neurotropin, a small nonprotein substance with pharmacologic activities, is extracted and then purified from the inflamed tissue of vaccinated rabbits. ${ }^{10,18}$ It has been shown to have a potential analgesic effect and is now mainly used to treat chronic pain, especially neuropathic pain. ${ }^{7,19}$ In this case, we first chose neurotropin as an adjuvant treatment and obtained satisfactory beneficial effects. After treatment with neurotropin, the patient's neuropathic pain resolved gradually, accompanied by recovery of sensory and motor function.

Effective neuroprotection offered by neurotropin has been confirmed in several types of experimental models. ${ }^{12,18,20}$ Neurotropin could function as an antinociceptive and neuroprotective agent by activating the descending pain inhibitory system $^{10}$ and by inhibiting different neurotransmitters or cytokines such as substance $\mathrm{P}$, nerve growth factor, brainderived neurotrophic factor, and even axonal transport. ${ }^{8,11,21}$ Neurotropin may be effective for children with neuropathic pain, but this drug is rarely used in children. It has been demonstrated that neurotropin has significant effects on juvenile headache. ${ }^{9}$ This case study first revealed its beneficial effect on SCI pain after epidural anesthesia. Thus, we consider neurotropin a promising drug for pain relief in childhood.

\section{Conclusion}

In summary, the present case is the first direct evidence that neurotropin may have the clinical potential for treating neuropathy caused by an epidural block in children. To fully determine the effect of neurotropin on pain relief, more studies elucidating the underlying mechanisms and clinical benefits are needed.

\section{Disclosure}

The authors report no conflicts of interest in this work.

\section{References}

1. Rowland JW, Hawryluk GW, Kwon B, Fehlings MG. Current status of acute spinal cord injury pathophysiology and emerging therapies: promise on the horizon. Neurosurg Focus. 2008;25(5):E2.

2. Devivo MJ. Epidemiology of traumatic spinal cord injury: trends and future implications. Spinal Cord. 2012;50(5):365-372.

3. Pradhan S, Yadav R, Maurya PK, Mishra VN. Focal myelomalacia and syrinx formation after accidental intramedullary lidocaine injection during lumbar anesthesia: a report of 3 cases. J Neurol Sci. 2006;251(1-2): $70-72$.

4. Pitkanen MT, Aromaa U, Cozanitis DA, Forster JG. Serious complications associated with spinal and epidural anaesthesia in Finland from 2000 to 2009. Acta Anaesthesiol Scand. 2013;57(5):553-564.

5. Makris A, Gkliatis E, Diakomi M, Karmaniolou I, Mela A. Delayed spinal epidural hematoma following spinal anesthesia, far from needle puncture site. Spinal Cord. 2014;52(Suppl 1):S14-S16.

6. Killeen T, Kamat A, Walsh D, Parker A, Aliashkevich A. Severe adhesive arachnoiditis resulting in progressive paraplegia following obstetric spinal anaesthesia: a case report and review. Anaesthesia. 2012;67(12): 1386-1394.

7. Kudo T, Kushikata T, Kudo M, Kudo T, Hirota K. Antinociceptive effects of neurotropin in a rat model of central neuropathic pain: DSP-4 induced noradrenergic lesion. Neurosci Lett. 2011;503(1):20-22.

8. Taneda K, Tominaga M, Tengara S, Ogawa H, Takamori K. Neurotropin inhibits both capsaicin-induced substance $P$ release and nerve growth factor-induced neurite outgrowth in cultured rat dorsal root ganglion neurones. Clin Exp Dermatol. 2010;35(1):73-77. 
9. Saito Y, Fukumura S, Saito T, et al. [Effect of neurotropin on chronic headaches in children]. No To Hattatsu. 2012;44(6):477-481. Japanese.

10. Okazaki R, Namba H, Yoshida H, Okai H, Miura T, Kawamura M. The antiallodynic effect of neurotropin is mediated via activation of descending pain inhibitory systems in rats with spinal nerve ligation. Anesth Analg. 2008;107(3):1064-1069.

11. Isonaka R, Takenami T, Katakura T, Kawakami T. Neurotropin inhibits axonal transport in cultured mouse dorsal root ganglion neurons. Neurosci Lett. 2013;543:101-104.

12. Avdoshina V, Becker J, Campbell LA, et al. Neurotrophins modulate the expression of chemokine receptors in the brain. JNeurovirol. 2011;17(1): 58-62.

13. Cox RG. From the journal archives: epidural anesthesia in young children: what have we learned in the past 60 years? Can JAnaesth. 2014;61(1): $72-75$.

14. Wilhelmi BJ, Blackwell SJ, Miller JH, et al. Do not use epinephrine in digital blocks: myth or truth? Plast Reconstr Surg. 2001;107(2):393-397.

15. Gulur P, Tsui B, Pathak R, Koury KM, Lee H. Retrospective analysis of the incidence of epidural haematoma in patients with epidural catheters and abnormal coagulation parameters. Br J Anaesth. 2015;114(5):808-811.
16. Meyer MJ, Krane EJ, Goldschneider KR, Klein NJ. Case report: neurological complications associated with epidural analgesia in children: a report of 4 cases of ambiguous etiologies. Anesth Analg. 2012;115(6): 1365-1370.

17. Mehta S, McIntyre A, Janzen S, Loh E, Teasell R. Systematic review of pharmacologic treatments of pain after spinal cord injury: an update. Arch Phys Med Rehabil. 2016;97(8):1381-1391. e1381.

18. Steiner JP, Nath A. Neurotrophin strategies for neuroprotection: are they sufficient? J Neuroimmune Pharmacol. 2014;9(2):182-194.

19. Okazaki R, Namba H, Yoshida H, Okai H, Taguchi K, Kawamura M. Combined antiallodynic effect of Neurotropin ${ }^{\circledR}$ and pregabalin in rats with L5-spinal nerve ligation. Life Sci. 2013;92(4-5):259-265.

20. Zhang RX, Lu ZH, Wan DS, et al. Neuroprotective effect of neurotropin on chronic oxaliplatin-induced neurotoxicity in stage II and stage III colorectal cancer patients: results from a prospective, randomised, single-centre, pilot clinical trial. Int J Colorectal Dis. 2012; 27(12):1645-1650.

21. Ishikawa T, Yasuda S, Minoda S, et al. Neurotropin ${ }^{\circledR}$ ameliorates chronic pain via induction of brain-derived neurotrophic factor. Cell $\mathrm{Mol} \mathrm{Neu}$ robiol. 2015;35(2):231-241.
Journal of Pain Research

\section{Publish your work in this journal}

The Journal of Pain Research is an international, peer reviewed, open access, online journal that welcomes laboratory and clinical findings in the fields of pain research and the prevention and management of pain. Original research, reviews, symposium reports, hypothesis formation and commentaries are all considered for publication.

\section{Dovepress}

The manuscript management system is completely online and includes a very quick and fair peer-review system, which is all easy to use. Visit http://www.dovepress.com/testimonials.php to read real quotes from published authors. 